\title{
Chemogenetic Inactivation of Ventral Hippocampal Glutamatergic Neurons Disrupts Consolidation of Contextual Fear Memory
}

\author{
Hu Zhu', Kristen E Pleil ',2, Daniel J Urban', Sheryl S Moy ${ }^{3,4}$, Thomas L Kash ${ }^{1,2}$ and Bryan L Roth ${ }^{* 1,3,5,6,7,8}$ \\ 'Department of Pharmacology, School of Medicine, University of North Carolina, Chapel Hill, NC, USA; ${ }^{2}$ Department of Pharmacology, \\ Bowles Center for Alcohol Studies, School of Medicine, University of North Carolina, Chapel Hill, NC, USA; ${ }^{3}$ Carolina Institute for \\ Developmental Disabilities, University of North Carolina, Chapel Hill, NC, USA; ${ }^{4}$ Department of Psychiatry, School of Medicine, \\ University of North Carolina, Chapel Hill, NC, USA; ${ }^{5}$ Program in Neuroscience, University of North Carolina, Chapel Hill, NC, USA; \\ ${ }^{6}$ Lineberger Comprehensive Cancer Center, University of North Carolina, Chapel Hill, NC, USA; ${ }^{7}$ Division of Chemical Biology and Medicinal \\ Chemistry, School of Pharmacy, University of North Carolina, Chapel Hill, NC, USA; ${ }^{8}$ NIMH Psychoactive Drug Screening Program, University \\ of North Carolina, Chapel Hill, NC, USA
}

Synaptic consolidation is a process thought to consolidate memory in the brain. Although lesion studies have mainly implicated the hippocampus (HPC) in this process, it is unknown which cell type(s) or regions of the HPC might be essential for synaptic consolidation. To selectively and reversibly suppress hippocampal neuronal activity during this process, we developed a new Gi-DREADD (hM4Di) transgenic mouse for in vivo manipulation of neuronal activity in freely moving animals. We found that CAI pyramidal neurons could be dose-dependently inactivated by clozapine-n-oxide (CNO). Inactivation of hippocampal neurons within $6 \mathrm{~h}$ immediately after conditioned fear training successfully impaired the consolidation of contextual memory, without disturbing cued memory. To anatomically define the brain subregion critical for the behavioral effects, hM4Di viral vectors were transduced and selectively expressed in the glutamatergic neurons in either the dorsal or ventral HPC. Significantly, we found that selective inactivation of ventral but not dorsal glutamatergic hippocampal neurons suppressed the synaptic consolidation of contextual memory.

Neuropsychopharmacology (2014) 39, I880-1892; doi:I0.1038/npp.20।4.35; published online I2 March 20I4

\section{INTRODUCTION}

Memory consolidation is a process whereby newly acquired information is thought to be stabilized gradually from an initial labile to a permanent state. In pioneering studies in 1900, Müller and Pilzecker (1900) found that newly learned memories can be disrupted by competing learning tasks conducted shortly after the original learning episode, suggesting that new memories are initially in a fragile state and gradually consolidate over time. Since then, a large number of studies have confirmed that new memories are susceptible to a variety of amnestic agents applied immediately after original learning, including electroconvulsive shock (Duncan, 1949), systemic or local infusion of protein synthesis inhibitor (Agranoff et al, 1965), and the genetic manipulation of signaling molecules (for example, cAMP response element-binding protein (CREB; Kida et al,

*Correspondence: Dr BL Roth, Department of Pharmacology, School of Medicine, University of North Carolina, 4072 Genetic Medicine Building, I20 Mason Farm Road, Chapel Hill, NC 27599, USA, Tel: + I 9199667535 , Fax: + I 919843 5788,

E-mail: bryan_roth@med.unc.edu

Received 30 September 2013; revised 3 February 2014; accepted 7 February 2014; accepted article preview online 14 February 2014
2002), N-methyl-D-aspartate receptor (NMDAR; Shimizu et al, 2000), or calcium/calmodulin-dependent protein kinase type ii subunit alpha ( $\alpha$-CaMKII; Lisman et al, 2002)). The susceptibility of newly learned memories to amnestic agents occurs only within a few hours after initial learning, and dramatically decreases thereafter (Bourtchouladze et al, 1998; Freeman et al, 1995; Grecksch and Matthies, 1980; Igaz et al, 2002). This relatively short time window reflects ongoing changes of intracellular signal transduction pathways and subsequent modulation of gene expression and protein synthesis in local neural circuits, which are all apparently vulnerable to amnestic agents.

The molecular and cellular changes occurring in the hippocampus (HPC) a few hours after learning, which are critical for memory consolidation, have been intensively investigated during the last two decades (Kandel, 2012; Lisman and Grace, 2005; McGaugh, 2000). Many molecules have been implicated in this process, including the NMDA receptor (Shimizu et al, 2000; Tsien et al, 1996), $\alpha$-CaMKII (Frankland et al, 2001), protein kinase A (PKA; Abel et al, 1997), protein kinase C (PKC; Sweatt, 1999) and extracellular signal-regulated kinases (ERKs; Chen et al, 2005) to name just a few. These signal transduction cascades trigger the activation of transcription factors (CREB, c-fos, and 
Early growth response protein 1 (Egr1)) and subsequent gene expression. These molecular changes are thought to lead to structural and morphological alterations and ultimately the modification of existing synapses in the local neural circuit (Frankland and Bontempi, 2005; McGaugh, 2000).

The HPC is not a unitary structure, and it is anatomically and functionally differentiated along its dorsoventral (septotmeporal) axis (Fanselow and Dong, 2010; Moser and Moser, 1998). Both the dorsal and ventral HPC has been implicated in the process of memory consolidation (Bast et al, 2001; Donley et al, 2005; Frankland et al, 1998; Maren et al, 1997; McNish et al, 2000; Trivedi and Coover, 2004), although the respective role(s) of each division and cell types within each division are unknown. To address the time window and the regional specificity of the HPC in memory consolidation, pharmacological, or genetic lesion methods have been applied to disrupt hippocampal function after the initial learning (Bast et al, 2001; Donley et al, 2005; Frankland et al, 1998; Maren et al, 1997; McNish et al, 2000; Trivedi and Coover, 2004). However, such overt alterations of hippocampal function could non-specifically disrupt other neuronal processes, which could then directly or indirectly modulate subsequent performance in memory tasks. In order to achieve a high degree of temporal, reversible, and noninvasive hippocampal neuron inactivation, we utilized both transgenic and virally transduced hM4Di DREADD (Designer Receptor Exclusively Activated by Designer Drug) technology. We found that chemogenetic inactivation of only the ventral hippocampal principal neurons by hM4Di within $6 \mathrm{~h}$ immediately after training impaired the consolidation of contextual memory. Our results demonstrate a striking and exquisite cell-type-specific control of a distinct phase and form of memory.

\section{MATERIALS AND METHODS}

\section{Generation of TRE-HA-hM4Di Mice}

Mice used in the present study were housed in ventilated cages, with free access to water and standard chow diet. The housing room had a 12-h light/dark cycle. All procedures were conducted in strict compliance with the 'Guide for the Care and Use of Laboratory Animals' and approved by the Institutional Animal Care and Use Committee of the University of North Carolina. Transgenic mice were produced by the UNC transgenic core facility. The HAtagged hM4Di sequence was cloned into pTRE-Tight plasmid and after digestion by XhoI/PvuI, $2.0 \mathrm{~kb}$ DNA fragments of TRE-HA-hM4Di were injected into pronucleus of C57BL/DBA2 hybrid mouse oocytes. Genotyping was performed by PCR of genomic DNA extracted from tail clips using the following primers: forward, 5'-ACCGTCAGATC GCCTGGAGA-3'; reverse, 5'-GACTGTCTGCAGCTGCCTG TTG-3'.

Upon identification, founder TRE-HA-hM4Di mice were crossed with mice carrying the tetracycline-controlled transactivator protein (tTA) driven by the CaMKII $\alpha$ promoter on a B6/CBA background (The Jackson Laboratory, Bar Harbor, ME, USA). These CaMKII $\alpha$-tTA mice have been described previously (Mayford et al, 1996). Double transgenic mice carrying both the TRE-HA-hM4Di and
CaMKII $\alpha$-tTA transgenes were identified as described above, with the addition of the primers: forward, $5^{\prime}$-CGCT GTGGGGCATTTTACTTTAG-3' and Reverse, 5'-CATGTCC AGATCGAAATCGTC-3'.

\section{Immunohistochemistry}

Immunohistochemistry was performed to verify expression of the HA-hM4Di protein as previously described (Abbas et al, 2009). Briefly, adult mice were anesthetized and perfused with $4 \%$ parafromaldehyde (PFA) in 1X PBS. Mouse brains were harvested, post-fixed with in 1X PBS/4\% PFA overnight, and then dehydrated in $1 \mathrm{X}$ PBS/30\% sucrose until they sank. Brain sections $(40 \mu \mathrm{m})$ were cut and mounted onto the coated microscope slides. Brain slides were permeabilized with $1 \mathrm{X}$ PBS $/ 0.4 \%$ Triton $\mathrm{X}-100$ for $1 \mathrm{~h}$, and then blocked with $1 \mathrm{X}$ PBS $/ 0.4 \%$ Triton X-100 solution containing $1 \%$ bovine serum albumin and $5 \%$ normal goat serum at room temperature for $1 \mathrm{~h}$. Rabbit monoclonal antiHA antibody (1:500, Cell Signaling) diluted in the blocking solution was applied to the slides and incubated at $4{ }^{\circ} \mathrm{C}$ overnight. Following the wash with $1 \mathrm{X}$ PBS/0.4\% Triton $\mathrm{X}-100$, slides were incubated with either AlexaFluor 488 or AlexaFluor 594 goat anti-rabbit antibody $(1: 250$, Invitrogen) diluted in the blocking solution at room temperature for $2 \mathrm{~h}$. Fluorescent images were collected on a Nikon $80 \mathrm{i}$ Research Upright Microscope (Nikon, Tokyo, Japan) equipped with the Surveyor Software with TurboScan (Objective Imaging, Kansasville, WI). Tiled images were collected with a Qimaging Retiga-EXi camera (Qimaging, Surrey, BC, Canada).

\section{Immunoprecipitation and Western Blot}

Immunoprecipitation (IP) and western blot were performed to confirm the expression of HA-hM4Di in the brain of CaMKII $\alpha$ - hM4Di double transgenic mice. Mice were deeply anesthetized and their brains were harvested. The brain tissues were homogenized in ice-cold standard binding buffer (SBB, $50 \mathrm{mM}$ Tris- $\mathrm{HCl}, \mathrm{pH}$ 7.4; $10 \mathrm{mM} \mathrm{MgCl}_{2} ; 0.1 \mathrm{mM}$ EDTA; plus protease and phosphatase inhibitor cocktails (Roche Diagnostics)) and centrifuged $20000 \mathrm{~g}$ for $30 \mathrm{~min}$ at $4{ }^{\circ} \mathrm{C}$. The pellets were re-suspended in $1 \mathrm{ml}$ RIPA buffer (50 mM Tris-Cl, pH 8.0; 150 mM NaCl, 0.1\% SDS, 1\% NP-40, $0.5 \% \mathrm{Na}$-deoxycholate, plus protease inhibitor cocktail) and allowed to lyse on ice for $30 \mathrm{~min}$. After centrifuging at maximum speed for $30 \mathrm{~min}$ at $4{ }^{\circ} \mathrm{C}$, detergent-soluble proteins $(4 \mathrm{mg})$ were pre-cleared with $50 \mu \mathrm{l}$ sepharose $4 \mathrm{~B}$ beads (Sigma), and then incubated with $50 \mu$ wheat germ agglutinin (WGA)-conjugated agarose beads (Vector Technology) overnight at $4{ }^{\circ} \mathrm{C}$ on a rotary mixer. After five washes with $1 \mathrm{ml}$ of RIPA buffer, WGA-bound proteins were eluted by incubating in $50 \mu \mathrm{l} 2 \mathrm{X}$ SDS sample buffer at $55^{\circ} \mathrm{C}$ for $10 \mathrm{~min}$. Whole WGA-bound proteins were separated using SDS-PAGE gel, transferred to PVDF membrane, and probed with rabbit monoclonal anti-HA antibody (1:500, Cell Signaling) and mouse monoclonal anti-transferrin antibody (1:1000, Invitrogen). The blot was incubated with chemiluminescent substrate (Thermo Scientific) and imaged in a Kodak Imager. 


\section{Electrophysiology}

Mice were decapitated under isoflurane anesthesia. Coronal slices $(300 \mu \mathrm{m})$ containing the dorsal HPC were prepared using a Leica VT1200 vibratome. Slices were transferred to a submerged recording chamber (Warner Instruments, Hamden, CT), where they were perfused with heated, oxygenated ACSF at a rate of $\sim 2 \mathrm{ml} / \mathrm{min}$ and allowed to equilibrate for $30 \mathrm{~min}$ before electrophysiological recordings. Pyramidal neurons in the CA1 subregion of the HPC were recorded under the infrared video microscopy (Olympus). Recording electrodes (3-5 M $\Omega$ ) filled with (in $\mathrm{mM}$ ) $135 \mathrm{~K}^{+}$gluconate, $5 \mathrm{NaCl}, 2 \mathrm{MgCl}_{2}, 10 \mathrm{HEPES}, 0.6$ EGTA, $4 \mathrm{Na}$ ATP, $0.4 \mathrm{Na}$ GTP, pH 7.3, 290-295 mOsmol were used to patch neurons. Electrical signals from neurons were acquired via a Multiclamp 700B amplifier, digitized at $10 \mathrm{kHz}$, and analyzed using the Clampfit 10.2 software (Molecular Devices, Sunnyvale, CA). Voltage-clamp configuration was used to access neurons at the onset of experiments to assess basal membrane properties. Several measures were taken to determine the effect of $\mathrm{CNO}$ on intrinsic excitability and current-evoked excitability of hippocampal neurons in control and double transgenic mice. First, current-injected firing was measured using a ramp protocol to determine the baseline rheobase of the neuron. Next, current-injected firing was assessed using a step protocol to examine the relationship between the magnitude of current injected and the number of action potentials fired, with each step increasing from the previous by $10 \mathrm{pA}$. Subsequently, baseline RMP was re-established, and CNO was bathapplied for $5 \mathrm{~min}$ to determine whether the concentration of CNO was sufficient to hyperpolarize the neuron. Another 5 min after CNO application, current injection protocols were performed again to determine whether application of $\mathrm{CNO}$ altered the ability of current injection to induce firing.

Statistical analyses were performed after first assessing the normality of distributions of data sets. Changes from baseline for RMP and rheobase were analyzed using paired $t$-tests between baseline and post-CNO values, and comparisons between groups were made using unpaired $t$-tests with Bonferroni's correction for multiple comparisons when appropriate. Welch's corrections were utilized when variances between groups were unequal. Effects of $\mathrm{CNO}$ on the relationship between the magnitude of current injection and number of action potentials were assessed using repeated measures ANOVA.

\section{Virus Production and Stereotaxic Injection}

The adeno-associated virus (AAV) CaMKII $\alpha:$ :HA-hM4DiIRES-mCitrine was constructed by cloning HA-hM4Di-IRESmCitrine into an AAV backbone carrying CaMKII $\alpha$ promoter using NheI and AscI restriction sites. The recombinant AAV vectors were stereotyped with AAV8 coat proteins and packaged by the Vector Core of the University of North Carolina at Chapel Hill. The titer was about $1 \times 10^{12}$ particles/ml. C57BL/6 mice were anesthetized by ketamine/ xylazine solution and secured in a stereotaxic apparatus (Kopf Instruments, Tujunga, CA), holes were drilled into the skull, and viruses were delivered bilaterally using a $10-\mu l$ syringe and metal needle (Hamilton, Reno, NV). The injection volume and flow rate were controlled by a syringe pump (Harvard apparatus, Holliston, MA). A pulse microinjection ( $40 \mathrm{nl} /$ injection, $80 \mathrm{nl} / \mathrm{s}$ rate, 15 injections/site) was performed to broaden the spread of the viral vector in the HPC. The needle was left in place for an additional 5 min after each injection to minimize upward flow of viral solution. Virus was microinjected bilaterally into dorsal HPC, ventral HPC, or both, using the following coordinates: dorsal HPC (anteroposterior (AP) $-2.2 \mathrm{~mm}$ from bregma, mediolateral (ML) $\pm 2.0 \mathrm{~mm}$, dorsoventral (DV) $-1.7 \mathrm{~mm}$ ), ventral HPC (AP $-3.2 \mathrm{~mm}$ from bregma, $\mathrm{ML} \pm 3.5 \mathrm{~m}, \mathrm{DV}-3.0 \mathrm{~mm}$ ).

\section{Basal Behavioral Tests}

CaMKII $\alpha$-hM4Di double transgenic mice and single transgenic littermate control mice underwent an extensive regimen of behavioral testing, to verify that DREADD expression had no intrinsic effects in the absence of CNO. Mice were $\sim 2$ months old when testing began. Tests were given in the following order, with one or two procedures per week: elevated plus maze, open field activity, light/dark preference, accelerating rotarod, social approach test, prepulse inhibition of acoustic startle responses, and spatial learning and memory in the Morris water maze. A separate set of wild-type mice with AAV viral microinjection into ventral HPC were tested for open field activity. Groups were AAV-CaMKII::EGFP and AAV-CaMKII $\alpha:$ HA-hM4Di. All measures were taken by an observer blind to mouse genotype. Data were analyzed using one-way or repeated measures analysis of variance (ANOVA). Fisher's protected least significant difference (PLSD) tests were used to compare group means when a significant $F$ value was determined. For all comparisons, significance was set at $P<0.05$. The detailed protocols of basal behavioral tests were shown in the Supplementary Data.

\section{Fear Conditioning}

The conditioned fear was evaluated using a Near-Infrared Video Fear Conditioning system (MED Associates, St Albans, $\mathrm{VT})$. In the training phase, mice receive three pairings of a $30-\mathrm{s}, 90 \mathrm{~dB}, 5 \mathrm{kHz}$ tone (conditioned stimulus, CS) and a 2-s, $0.6 \mathrm{~mA}$ foot shock (unconditioned stimulus, US). Contextual memory was evaluated in the original training chamber $24 \mathrm{~h}$ following the training phase. Cued memory was evaluated in the different context $48 \mathrm{~h}$ following the training phase. Levels of freezing (no movement for $0.5 \mathrm{~s}$ ) were automatically measured by the image tracking software (Med Associates, St Albans, VT).

The effects of hippocampal inactivation on conditioned fear in CaMKII $\alpha$-hM4Di double transgenic mice and control mice were investigated in three separate experiments. In the first study, saline or CNO (2 mg/kg) was administered at 0,2 , and $4 \mathrm{~h}$ immediately after training, either given standard mouse chow, or following a 4-week regimen of DOX-containing chow (to inhibit expression of HA-hM4Di). In a second study, the window for $\mathrm{CNO}$ administration was shifted, so that $\mathrm{CNO}$ $(2 \mathrm{mg} / \mathrm{kg})$ was administered at 6,8 , and $10 \mathrm{~h}$ following training. In a third study, CNO $(2 \mathrm{mg} / \mathrm{kg})$ was administered at 0,2 , and $4 \mathrm{~h}$ immediately after training and mice were tested for contextual memory 1 month later. The role of hippocampal subregions on memory consolidation was investigated using AAV8-CaMKII $\alpha$ ::HA-hM4Di-IRES-mCitrine 
viruses to selectively express hM4Di in either dHPC, vHPC, or both hippocampal regions. In these studies, CNO $(2 \mathrm{mg} / \mathrm{kg})$ was administered at 0,2 , and $4 \mathrm{~h}$ immediately after training.

Statistical analyses were performed after first assessing the normality of distributions of data sets. Comparisons between groups were made using unpaired $t$-tests. Welch's corrections were utilized when variances between groups were unequal. Comparisons between groups during conditioning, contextual, and cued memory tests were assessed using repeated measures ANOVA.

\section{RESULTS}

\section{Generation and Characterization of CaMKII $\alpha$-hM4Di Double Transgenic Mice}

In previous studies, we demonstrated that hM4Di DREADD, when activated by clozapine-n-oxide (CNO), can hyperpolarize and silence cultured hippocampal neurons by inducing a $G$ protein-coupled inwardly-rectifying potassium channel (GIRK) response in vitro (Armbruster et al, 2007). To determine whether expression of hM4Di can modulate hippocampal principal cell neuronal activity in vivo, we developed a transgenic mouse line using the Tet-off system to achieve tissue-specific and tetracycline-controlled expression of HA-tagged hM4Di. Three founder lines were generated by pronuclear injection of C57BL/DBA2 hybrid mouse oocytes and crossed with mice carrying the tetracycline-controlled tTA under the control of forebrainspecific CaMKII $\alpha$ promoter (Figure 1a-c). The expression of HA-hM4Di protein was verified in double transgenic progeny by IP/western blot and immunostaining. The HA-hM4Di protein was revealed to migrate predominantly as a single $45 \mathrm{kD}$ band in IP/western blot (Figure 1d). One line (line 2) with higher receptor expression was selected for further characterization. In this line, HA-hM4Di immunofluorescence was detected in the HPC, cortex, and striatum (Figure 1e-h). The most intense signals were found in the subiculum of the HPC, which receives inputs from CA1 and entorhinal cortical pyramidal neurons and is the main output of the HPC. Hereafter, we refer to the double transgenic mice from this line as CaMKII $\alpha$-hM4Di mice and their single transgenic littermate mice as control mice.

In the Tet-off system, the tetracycline derivative, DOX, can bind tTA and render it incapable of binding to TRE sequences, thereby preventing transactivation of target genes. To examine DOX-controlled expression, double transgenic mice were fed with DOX-containing chow (200 mg/kg) for 4 weeks. IP/western blot and immunostaining revealed undetectable expression of the HA-hM4Di protein (Figure $1 \mathrm{~d}$ and $\mathrm{i}$ ). The results verified that HAhM4Di expression can be temporally controlled by DOX.

\section{Functional Inhibition of Hippocampal Neurons in CaMKII $\alpha$-hM4Di Double Transgenic Mice by CNO Administration}

To verify the functionality of hM4Di expressed in principal cells of the HPC, we first assessed the effects of 1 and $10 \mu \mathrm{M}$ $\mathrm{CNO}$ on the resting membrane potential (RMP) of hippocampal CA1 neurons in CaMKII $\alpha$-hM4Di double transgenic mice and control mice (Figure 2a-c). A comparison of baseline and post-CNO values revealed that $10 \mu \mathrm{M}$ CNO did not alter the RMP of hippocampal neurons in control mice $(p>0.45)$. In double transgenic mice, $1 \mu \mathrm{M}$ CNO produced a small but significant hyperpolarization of CA1 neurons $(t(3)=3.38, p=0.043)$, whereas $10 \mu \mathrm{M}$ CNO produced a large hyperpolarization $(t(5)=7.42, p<0.001)$, which was significantly larger than the $1 \mu \mathrm{M}$ dose $(t(8)=4.05, p=0.004$; see Figure $2 \mathrm{a}-\mathrm{c})$. DOX pretreatment for 4 weeks in CaMKII $\alpha$-hM4Di double transgenic mice completely ablated the ability of $10 \mu \mathrm{M}$ CNO to hyperpolarize CA1 neurons $(p>0.75)$. Further, there were no differences in baseline RMP between CA1 neurons in control and double transgenic mice (control: $-68.4 \pm 4.0 \mathrm{pA}$, double transgenic: $-63.3 \pm 1.5 \mathrm{pA} ; p>0.15$ ), suggesting that the effects of CNO on the RMP of neurons in double transgenic mice were likely not due to differences in either cell health or the basal properties of the cells.

We also assessed the effects of CNO on current-injection firing in these hippocampal neurons (Figure $2 \mathrm{~d}$ and e). We found that bath application of $10 \mu \mathrm{M}$ CNO significantly increased the rheobase (magnitude of current injection required to produce an action potential) in double transgenic mice $(t(4)=3.87, p=0.018)$, although not in control mice $(p>0.75)$. Further, $1 \mu \mathrm{M} \mathrm{CNO}$ was unable to alter the rheobase in double transgenic mice $(p>0.90)$, and $10 \mu \mathrm{M}$ $\mathrm{CNO}$ was unable to alter the rheobase in double transgenic mice pretreated with DOX $(p>0.95)$. A comparison between doses in CaMKII $\alpha$-hM4Di mice showed that the effect of $10 \mu \mathrm{M}$ CNO was significantly greater than that of $1 \mu \mathrm{M}$ $(t(7)=2.48, p=0.042$, Figure $2 \mathrm{~d}$ and e). However, there were no differences in the baseline rheobase between CA1 neurons between doses (unpaired $t$-test with Welch's correction; $p>0.25$ ), suggesting that the effects of $\mathrm{CNO}$ on the rheobase of neurons in double transgenic mice were likely not due to differences in cell health or basal ability of neurons to fire.

An evaluation of the effect of $\mathrm{CNO}$ on the relationship between the magnitude of current injection and number of action potentials showed that in control mice $10 \mu \mathrm{M}$ CNO did not alter the number of action potentials per magnitude of current injection from baseline values in CA1 neurons, demonstrated by a main effect of time $(F(1,20)=12.5$, $p<0.001)$ but lack of main effect of $\mathrm{CNO}$ and a lack of interaction between CNO and current magnitude ( $p$ 's $>0.95)$. A similar result was found with the $1 \mu \mathrm{M}$ dose in double transgenic mice (time: $\mathrm{F}(1,20)=26.6, p<0.001$; other $p$ 's $>0.95)$. On the other hand, $10 \mu \mathrm{M} \mathrm{CNO}$ in double transgenic mice significantly decreased the number of action potentials per current magnitude, revealed by a significant interaction between time and $\mathrm{CNO}(\mathrm{F}(1,20)=1.84, p=0.020)$, as well as a main effect of time $(\mathrm{F}(1,20)=53.9, p<0.001)$ and a trend toward a main effect of $\mathrm{CNO}(\mathrm{F}(1,20)=4.07$, $p=0.078$; Supplementary Figure S1). However, this effect was ablated in mice pretreated with DOX, indicated by a main effect of time $(\mathrm{F}(1,20)=14.7, p<0.001)$ but no effect of $\mathrm{CNO}$ or interaction $(p$ 's $>0.65)$. Taken together, our results suggest that CNO dose-dependently decreases CA1 neuronal intrinsic excitability in CaMKII $\alpha-\mathrm{hM} 4 \mathrm{Di}$ mice, thus functionally inhibiting the firing of CA1 neurons. In control mice, however, CNO did not alter any measures of excitability, demonstrating that the effects of $\mathrm{CNO}$ in double transgenic mice were not due to nonspecific effects of CNO. 


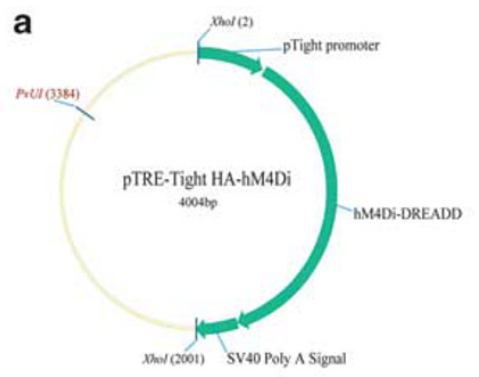

C

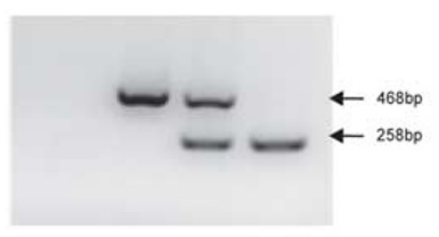

TTA hM4Di

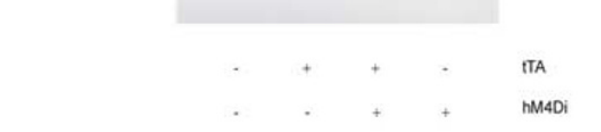

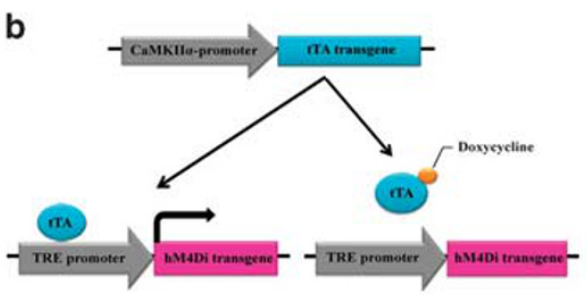

d

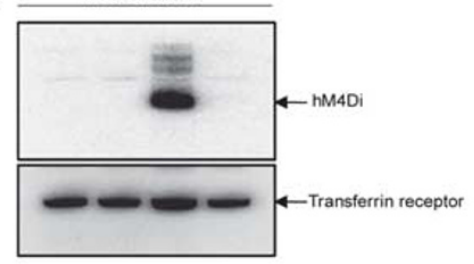

hM4Di

ITA

DOX
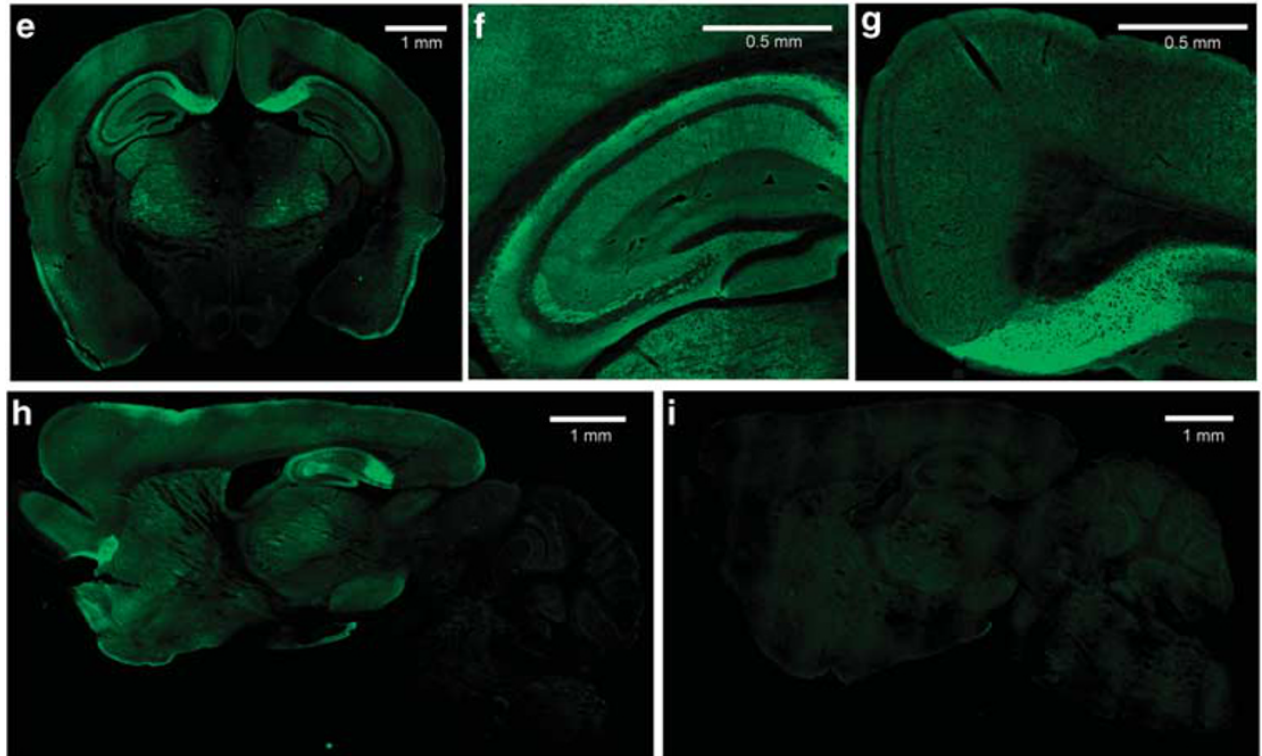

Figure I Generation and characterization of CaMKIl $\alpha$-hM4Di double transgenic mice. (a) The construct used for generation of TRE-hM4Di transgenic mice. The 2.0-kb Xhol-digested DNA fragments containing TRE-HA-hM4Di were injected into the pronucleus of C57BL/DBA2 hybrid mouse oocytes, and a transgenic mouse was produced. (b) Generation of CaMKIl $\alpha$-hM4Di mice. TRE-hM4Di transgenic mouse was crossed with a CaMKIl $\alpha$ ( tetracyclinecontrolled transactivator protein)-tTA driver line to produce double transgenic mice (CaMKIl $\alpha$-hM4Di). In double transgenic mice, tTA protein binds to the TRE promoter to activate the HA-hM4Di gene. In the presence of DOX, tTA protein cannot bind to TRE sequences and the transactivate HA-hM4Di gene. (c) Genotyping of CaMKIl $\alpha$-hM4Di double transgenic mice. Lower band (258 bp) represents the TRE-HA-hM4Di transgene, and upper band (468 bp) represents the CaMKIl $\alpha$-tTA transgene. (d) Detection of the HA-hM4Di protein in double transgenic mice by IP/western blot. Mouse forebrain membrane proteins were immunoprecipitated by WGA beads, and then blotted by anti-HA antibody. The HA-hM4Di protein was detected as a 45-kD protein band. The expression of HA-hM4Di was undetectable when double transgenic mice were maintained on DOX-containing food for 4 weeks. (e-i) Localization of the HA-hM4Di protein in double transgenic mice. Coronal sections $(\mathrm{e}-\mathrm{g})$ of CaMKIll-hM4Di mouse brain were stained with anti-HA antibody. The results showed that HA-hM4Di was expressed in pyramidal neurons of mouse forebrain, particularly in the hippocampus. Sagittal sections of double transgenic mouse brain were stained with anti-HA antibody with either normal chow (h) or DOX chow (i). The signals of HA-hM4Di were undetectable when double transgenic mice were maintained on DOX chow for 4 weeks.

\section{Selective Disruption of Contextual Memory Consolidation in CaMKII $\alpha$-hM4Di Double Transgenic Mice}

To determine whether the CaMKII $\alpha$-hM4Di mice have any intrinsic behavioral changes in the absence of $\mathrm{CNO}$,
CaMKII $\alpha$-hM4Di double transgenic mice and littermate control mice were examined in a battery of neurobehavioral tests in their naive state. CaMKII $\alpha$-hM4Di mice showed normal growth, body weights, and mating behavior. Locomotion, anxiety, motor coordination, sociability, and sensorimotor gating were comparable between the double 
a

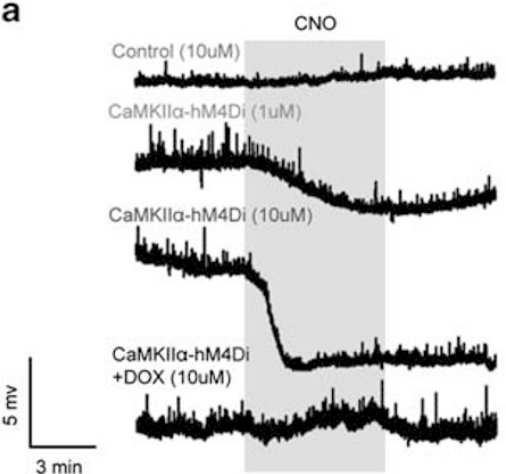

d

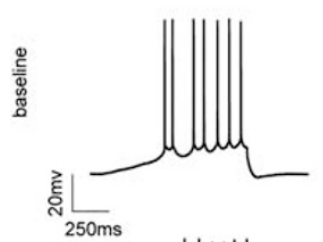

总

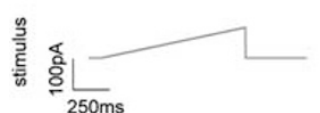

b

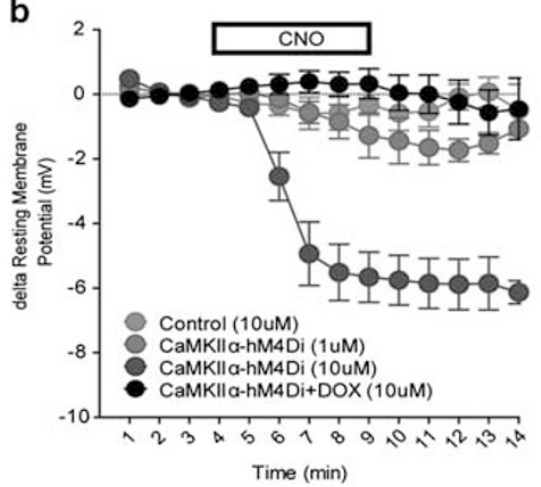

CaMKIla-hM4Di (10uM)
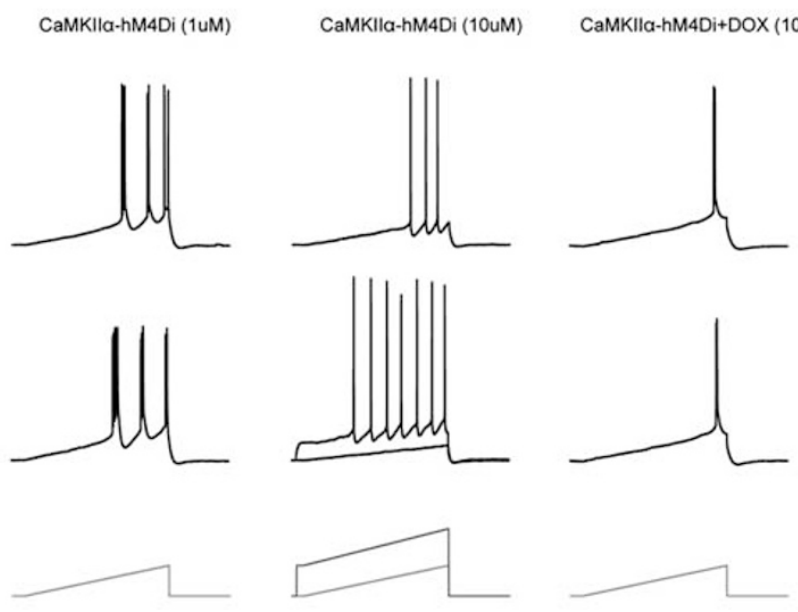
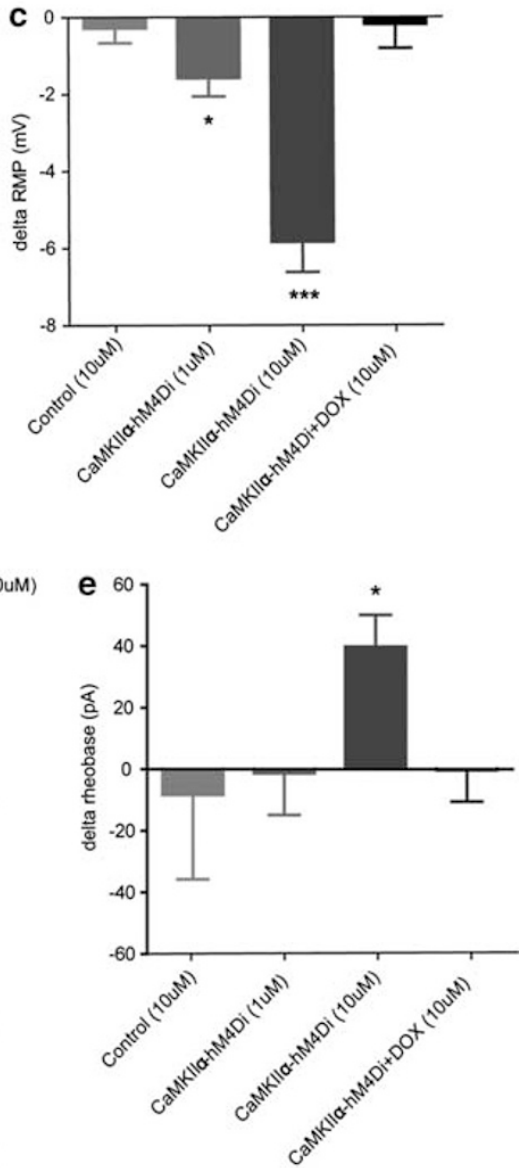

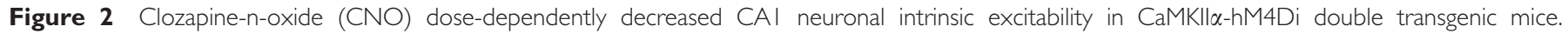
(a) Representative traces of resting membrane potential (RMP) from current-clamp electrophysiological recordings of CAI pyramidal neurons in

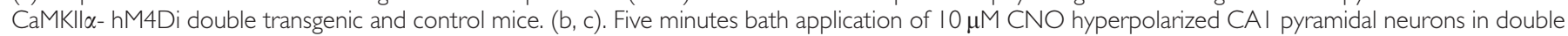

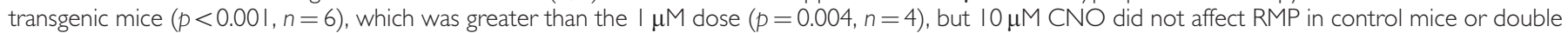

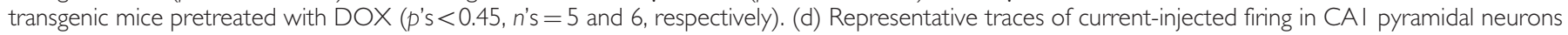

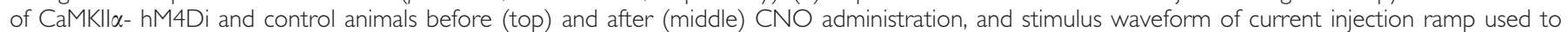

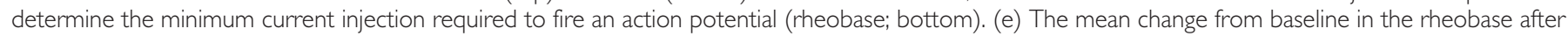

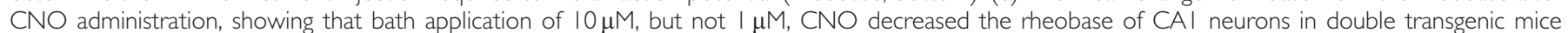

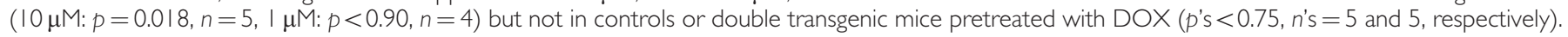

transgenic and littermate control mice, as demonstrated in open-field, elevated plus maze, light/dark preference, accelerating rotarod, social approach, and prepulse inhibition of acoustic startle responses (PPI) paradigms (Figure 3a-h, Supplementary Figure S2). These data showed that there are no baseline behavioral differences between double transgenic mice and control mice, in the absence of CNO.

To determine whether hippocampal expression of hM4Di has intrinsic effects on learning and memory, we evaluated the performance of double transgenic mice in a classical contextual and cued-fear conditioning paradigm. In the absence of CNO, CaMKII $\alpha$-hM4Di and littermate control mice showed comparable learning in tests of contextual and cued memory (Figure 4e). We further examined spatial memory in these mice using the Morris water maze procedure. There were no significant differences between double transgenic and littermate control mice in spatial learning and memory in the water maze (Figure $3 i$ and $f$ ). The results suggested that expression of hM4Di in principle cells of HPC throughout development has no intrinsic effects on acquisition, consolidation, and retrieval of longterm memory.

Previous studies have shown that the synaptic consolidation of contextual memory develops within several hours after training (Freeman et al, 1995; Grecksch and Matthies, 1980; Igaz et al, 2002). Therefore, we hypothesized that inactivation of hippocampal neurons by CNO within $6 \mathrm{~h}$ after the initial training might block the synaptic consolidation of contextual memory. Double transgenic and control mice were presented with three pairings of tone (CS) and foot-shock (US), and then injected with three doses of CNO $(2 \mathrm{mg} / \mathrm{kg})$ at 0,2 , and $4 \mathrm{~h}$ after training. Contextual and cued memory was assessed 24 and $48 \mathrm{~h}$ later, respectively, using measures of freezing (immobility; Figure 4a). Contextual memory requires both $\mathrm{HPC}$ and amygdala to form and retrieve the context-fear association (HPC-dependent), whereas cued memory only requires amygdala to form and retrieve the discrete cue-fear association (HPC-independent; Maren and Fanselow, 1996). CaMKII $\alpha$-hM4Di and 
a

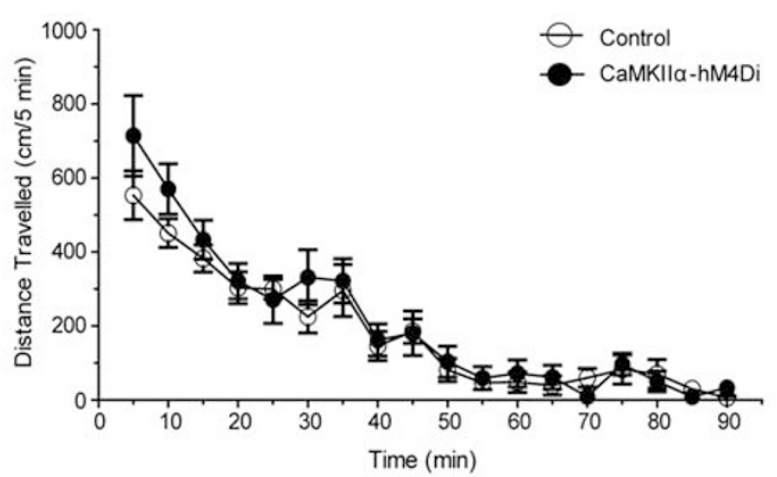

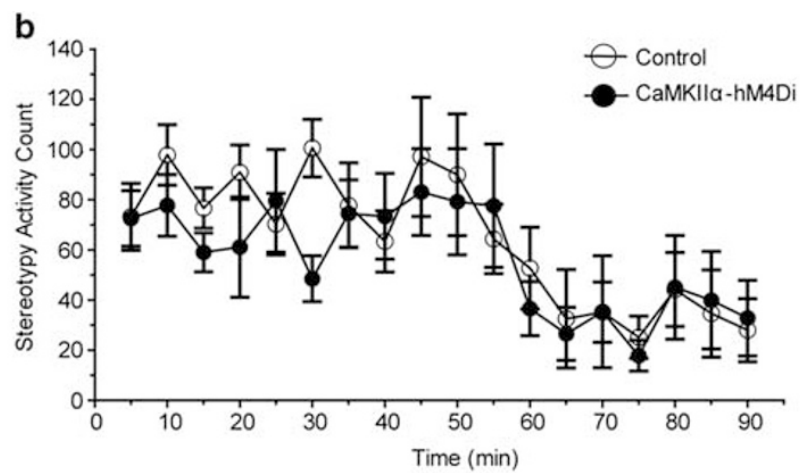

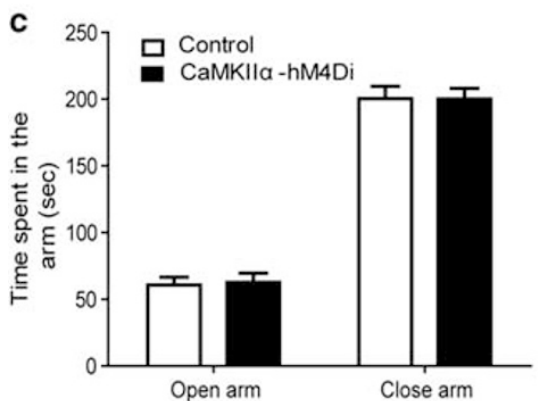

d
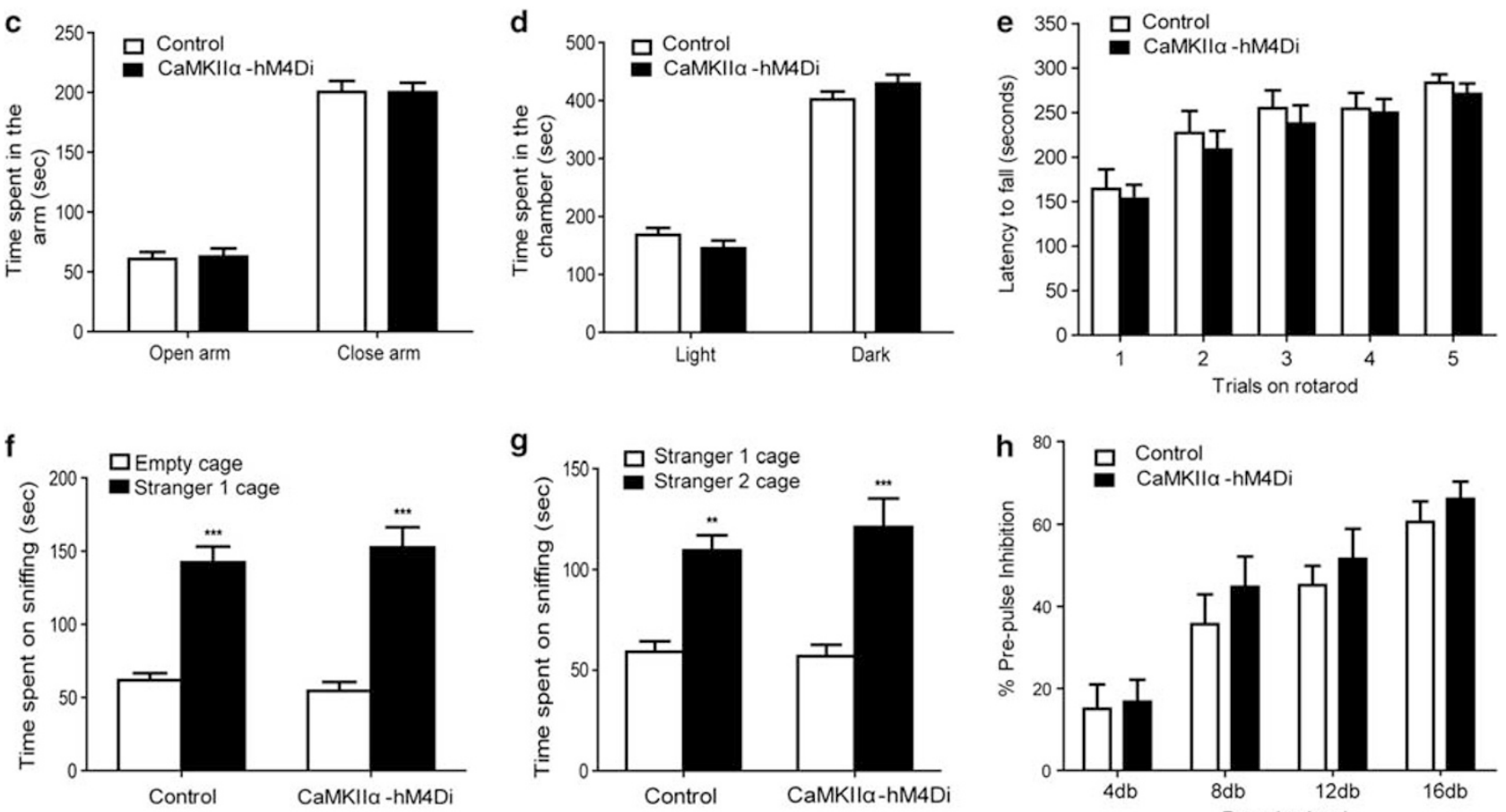

g
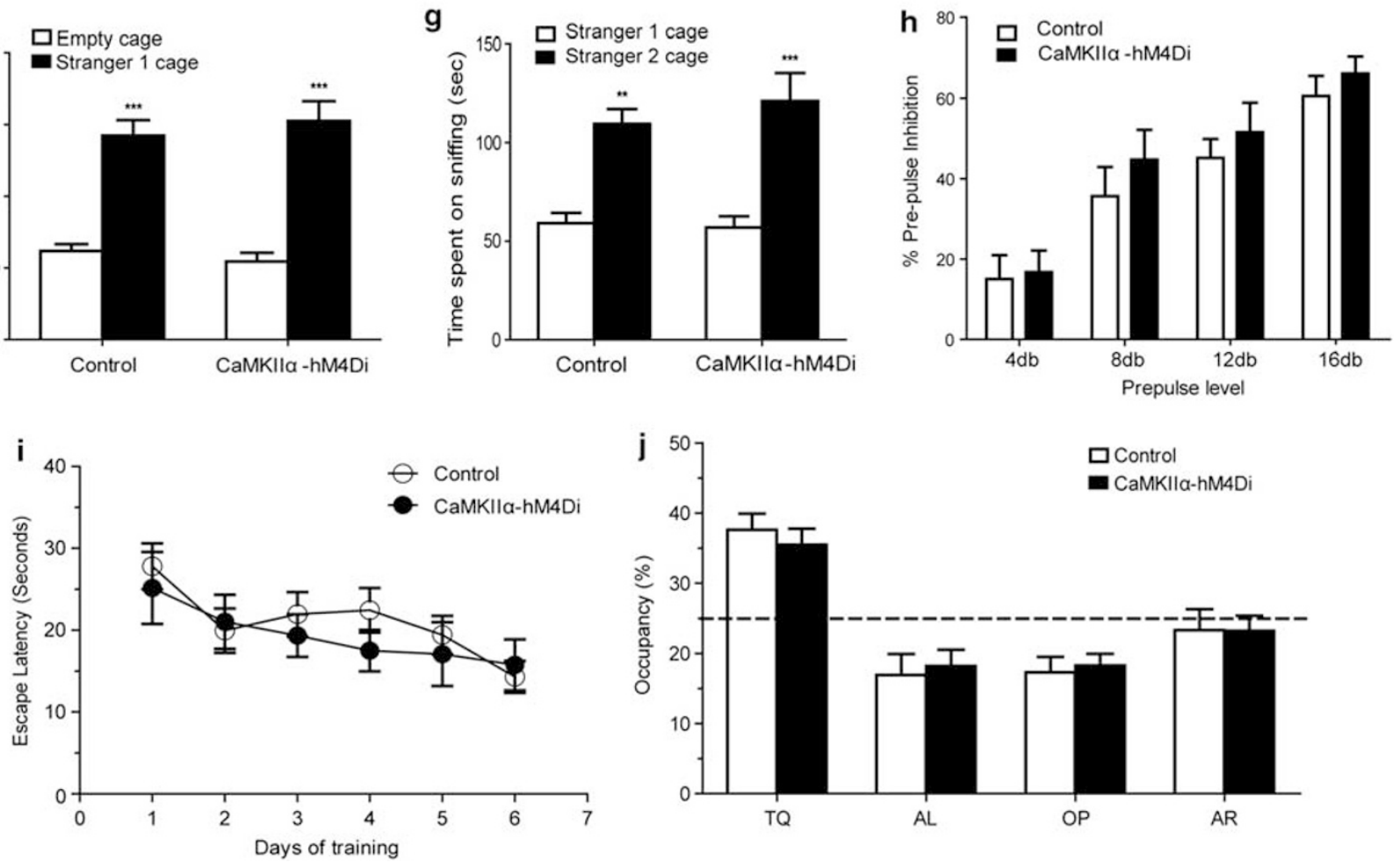

Figure 3 CaMKIl $\alpha$-hM4Di mice exhibited normal basal behaviors in the absence of clozapine-n-oxide (CNO). CaMKIl $\alpha$-hM4Di double transgenic mice and littermate control mice were examined in a battery of neurobehavioral tests in their naive state. CaMKIl $\alpha$-hM4Di double transgenic mice showed a comparable behavior in novelty induced locomotion $(a, p=0353, n=1 \mathrm{I})$ and stereotypy activity $(b, p=0.336, n=1 \mathrm{I})$. Double transgenic mice showed a normal anxiety level in the elevated plus maze test (c, $p=0.494, n=9)$ and light/dark preference test $(\mathrm{d}, p=0.359, n=9)$. In the accelerating rotarod test, hM4Di double transgenic mice showed a normal motor coordination $(e, p=0.489, n=9)$. In the sociability and social novelty test, hM4Di double transgenic mice showed a comparable preference compared with the littermate control mice (sociability, ( $f$ ) $p=0.843, n=9$; social novelty, (g) $p=0.621$, $n=9$ ). Double transgenic mice also showed a normal sensory-motor gating in prepulse inhibition test $(h, p=0.279, n=7)$. In the Morris water maze test, hM4Di double transgenic mice showed a comparable escape latency during learning ((i) $p=0.395, n=7)$ and preference to the target quadrant during the memory test $((j) p=0.934, n=7)$. 


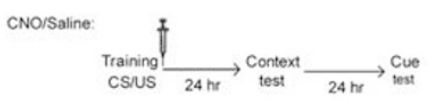

DOX+CNO:

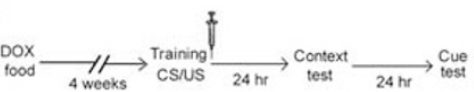

b

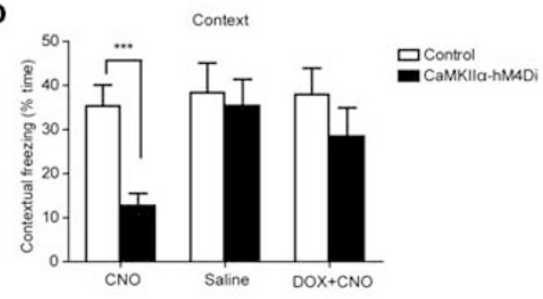

C

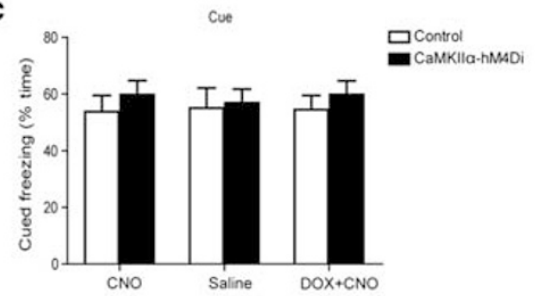

$\mathbf{d}_{80}$
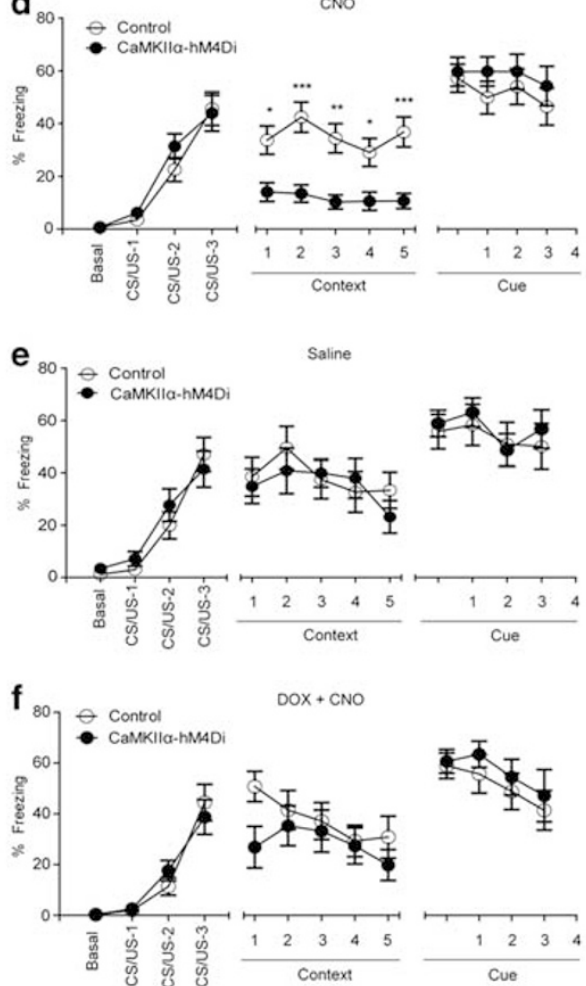
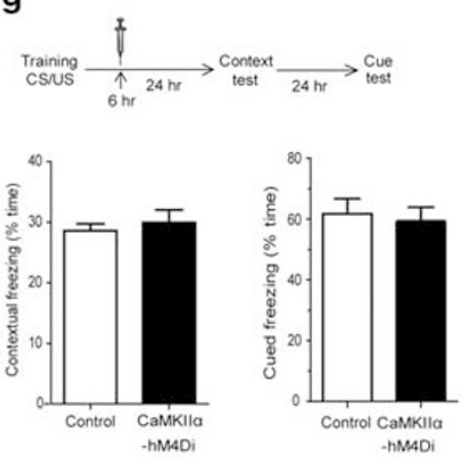

h
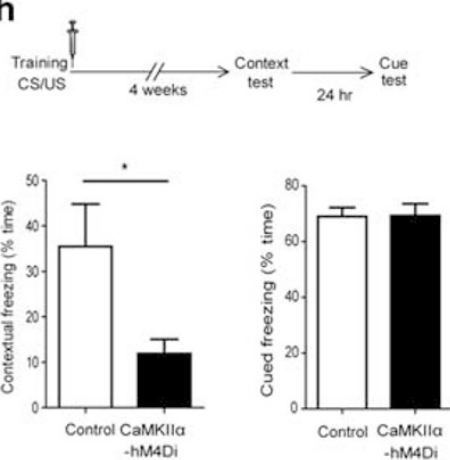

Figure 4 Consolidation of contextual memory was disrupted in CaMKIl $\alpha$-hM4Di mice when clozapine-n-oxide (CNO) was administrated immediately after training. (a) Experimental time-line for the fear-conditioning paradigm (b-f). Three doses of CNO $(2 \mathrm{mg} / \mathrm{kg})$ or saline were administrated at 0,2 , and $4 \mathrm{~h}$ after training. (b) Double transgenic mice showed a significant decrease in contextual freezing in CNO group $(p=0.0003, D T g, n=16$, control, $n=17)$ but not in saline group $(p=0.744, n=15)$ or DOX + CNO group $(p=0.294, n=12)$. (c) There was no significant difference in cued freezing between two genotypes in all groups. $(\mathrm{d}-\mathrm{f})$ There was a comparable performance during training between two genotypes in all three groups. Contextual memory was shown as the percentage of freezing time in a I-min block during 5-min test. Only the CNO groups showed a significant difference between double transgenic and control mice ( $p=0.0003)$. The cued memory was shown as the percentage of freezing time during the tone (CS). There was no significant difference between two genotypes in all groups. (g) Contextual memory was not impaired in double transgenic mice when CNO (2 mg/kg) was given 6, 8 , and $10 \mathrm{~h}$ after training. Double transgenic mice showed no significant difference in contextual memory $(p=0.555 \mathrm{DTg}, n=9, \mathrm{control}, n=\mathrm{I} \mathrm{I})$. (h) Remote contextual memory was impaired in double transgenic mice when CNO $(2 \mathrm{mg} / \mathrm{kg})$ was given at 0,2 , and $4 \mathrm{~h}$ after training, and contextual learning tested I month later. CaMKIl $\alpha$-hM4Di mice exhibited a significant decrease in contextual memory $(p=0.045$, DTg, $n=8$, control, $n=9)$.

control mice exhibited similar levels of freezing behavior during the initial training phase (Figure $4 \mathrm{~d}$ ). However, there was a dramatic decrease of freezing in double transgenic mice during the retrieval of contextual memory $(t(31)=4.059, p=0.0003$; Figure $4 \mathrm{~b}$ and $\mathrm{d})$, without any concomitant group differences in the cued memory test $(t(31)=0.7858, p=0.438$; Figure $4 c$ and $d)$. The data indicate that inactivation of hippocampal neurons by $\mathrm{CNO}$ impairs the synaptic consolidation of HPC-dependent contextual memory but not HPC-independent cued memory. To exclude off-target effects of CNO, the expression of hM4Di transgene was attenuated in double transgenic mice using DOX food administration for 4 weeks, and then mice were tested in the fear-conditioning paradigm. There was no significant difference between double transgenic mice and control mice in the retrieval of contextual memory $(t(22)=1.076, p=0.294$; Figure $4 \mathrm{~b}$ and $\mathrm{f}$ ) after the suppression of hM4Di expression.

To determine whether the 6-h time window after training is the most critical period for synaptic consolidation, we injected mice with three doses of CNO $(2 \mathrm{mg} / \mathrm{kg})$ at later time points $(6,8$, and $10 \mathrm{~h}$ after training), and then tested contextual fear memory $24 \mathrm{~h}$ later. The results showed that there was no significant difference in freezing between double transgenic mice and control mice during the contextual memory test $(t(18)=0.6011, p=0.555$, Figure $4 \mathrm{~g}$ ), which suggested that initial synaptic consolidation had been completed by $6 \mathrm{~h}$ after training. To determine whether the disruption of initial synaptic consolidation within $6 \mathrm{~h}$ after training has persistent effects on contextual memory, double transgenic and control mice were given three doses of $\mathrm{CNO}(2 \mathrm{mg} / \mathrm{kg})$ at 0,2 , and $4 \mathrm{~h}$ after training. Remote contextual memory was examined 1 month following the training phase. CaMKII $\alpha$-hM4Di mice exhibited a significant decrease in freezing, compared with the control mice $(t(16)=2.173, p=0.045$; Figure $4 \mathrm{~h})$. These findings indicate that disruption of the initial synaptic consolidation phase leads to long-term impairment of contextual memory.

\section{Ventral, but not Dorsal, Hippocampal Principal Cells are Involved in Synaptic Consolidation of Contextual Memory}

Although the $h M 4 D i$ gene was highly expressed in the HPC of double transgenic mice, expression also occurred in the 


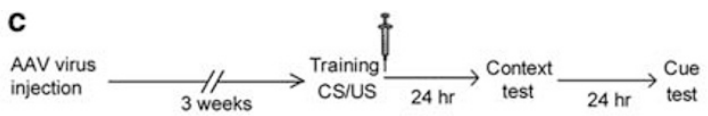

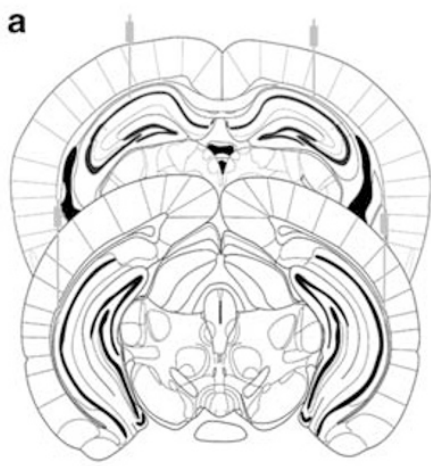

vHPC (Bregma - $3.27 \mathrm{~mm}$ )
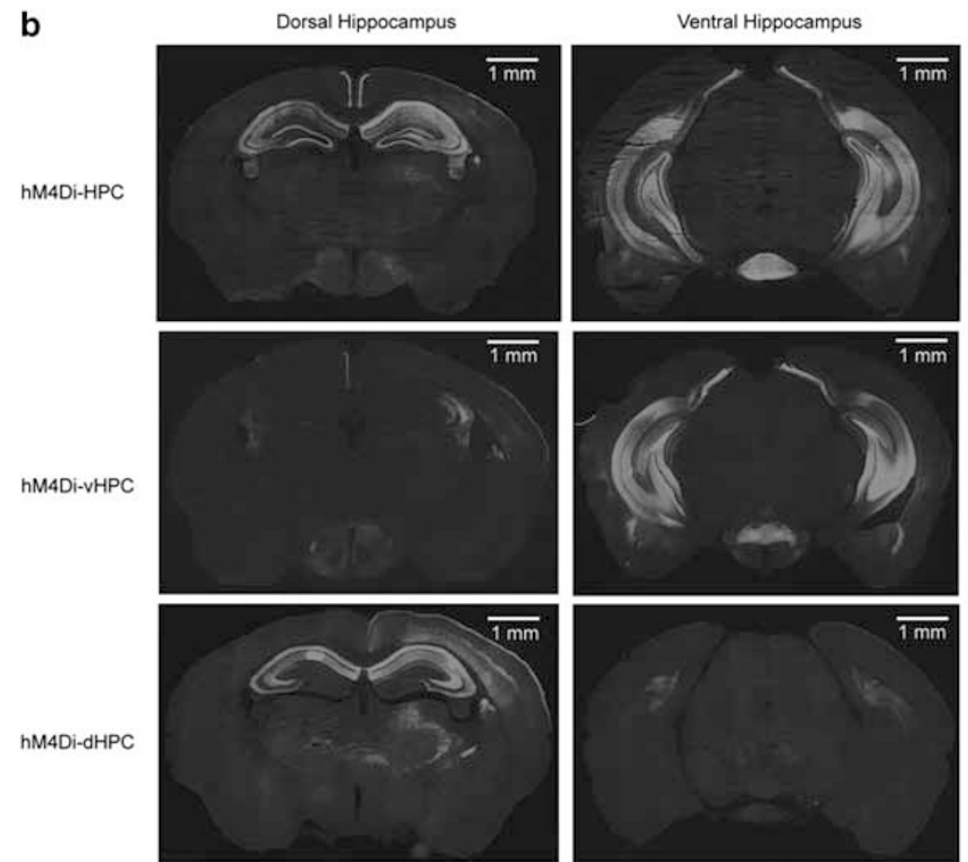
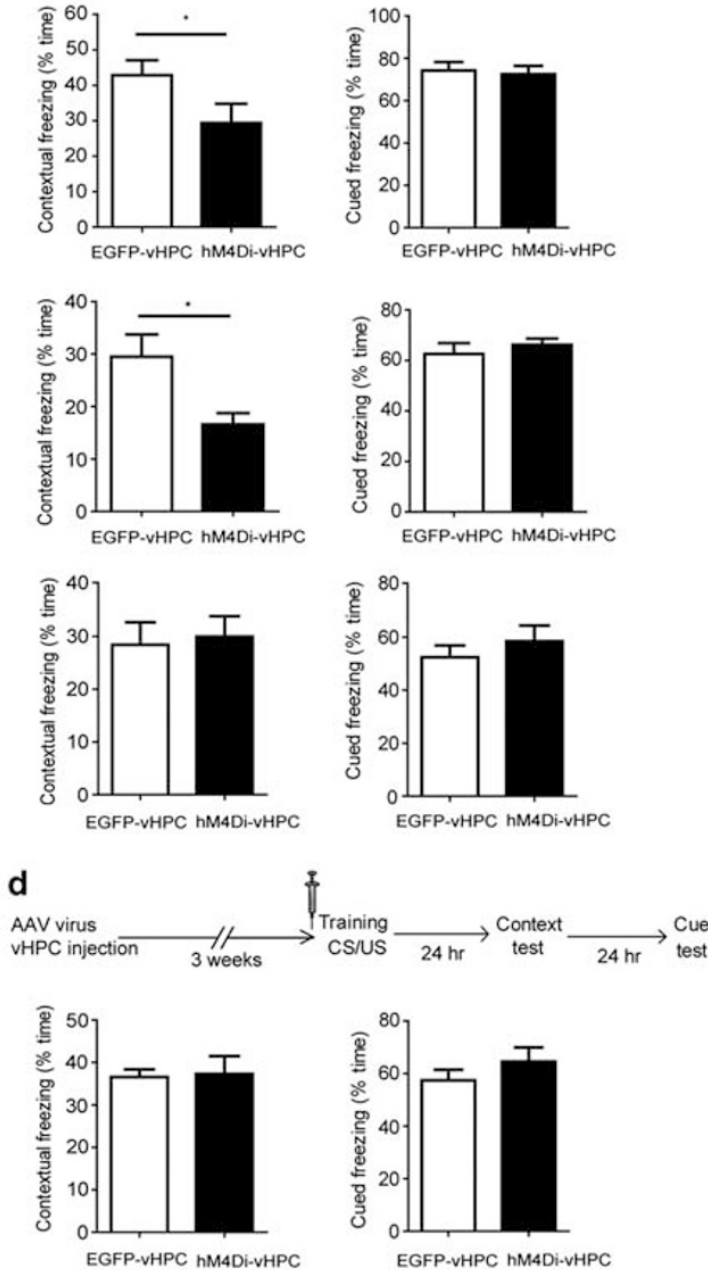

Figure 5 Ventral, but not dorsal, hippocampus was involved in synaptic consolidation of contextual memory. (a) Schematic representation of viral delivery

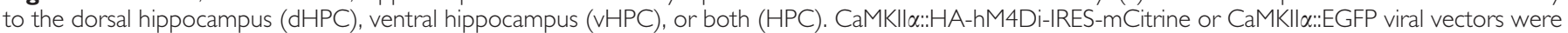
bilaterally injected into dHPC, vHPC, or both. (b) Immunostaining of mouse brain delivered with CaMKIl $\alpha:$ :HA-hM4Di-IRES-mCitrine virus. HA-hM4Di was expressed in the dorsal hippocampus, ventral hippocampus, or both in hM4Di-dHPC, hM4Di-vHPC, or hM4Di-HPC mice, respectively. Scale bar: I mm. (c) Ventral, but not dorsal, hippocampus was involved in synaptic consolidation of contextual memory. Three weeks after viral delivery, animals were trained and administrated with three doses of clozapine-n-oxide (CNO; $2 \mathrm{mg} / \mathrm{kg}$ ) at 0,2 , and $4 \mathrm{~h}$ after training. Contextual and cued memories were tested 24 and $48 \mathrm{~h}$ later, respectively. Mice with HA-hM4Di viruses injected into both dHPC and vHPC showed a significant decrease in contextual memory compared with the control mice $(p=0.047, n=8)$. Mice with HA-hM4Di viruses injected into only VHPC showed a significant decrease in contextual memory $(p=0.015, n=10)$. However, mice with HA-hM4Di virus injected into only dHPC showed a similar freezing compared with the control mice in contextual memory $(p=0.795, n=7)$. (d) Synaptic consolidation was not impaired by administration of CNO before training in hM4Di-vHPC mice. HA-hM4Di viruses were delivered to the VHPC. Three weeks later, mice were administrated with CNO $(2 \mathrm{mg} / \mathrm{kg}) 30 \mathrm{~min}$ before, instead of after training. There was no significant difference in contextual memory between hM4Di-vHPC and control mice $(p=0.87, n=9)$.

cortex and stratium. To confirm the role of HPC in the synaptic consolidation of contextual memory, we initially stereotaxically delivered the AAV encoding CaMKII $\alpha:$ HAhM4Di-IRES-mCitrine into the HPC. To cover the majority of the HPC, virus was bilaterally microinjected into two portions of HPC, dorsal (dHPC) and ventral HPC (vHPC; Figure 5a). A pulse injection technique was applied to broaden the spread of the viral vector in the HPC. As shown in Figure 5b, HA-hM4Di was highly expressed in both dHPC and vHPC, where it was expressed in the pyramidal neurons, but not in the parvalbumin-positive neurons, in HPC (Supplementary Figure S4). Three weeks later, animals were trained and given three doses of CNO at 0,2 , and $4 \mathrm{~h}$ post training. Similar to the results obtained with the transgenic mouse line, the animals injected with HA-hM4Di virus showed a significant decrease in freezing during the retrieval of contextual memory $(t(14)=2.183$, $p=0.047)$, but not the retrieval of cued memory $(\mathrm{t}(14)=0.304, p=0.785)$, compared with EGFP control mice (Figure $5 \mathrm{c}$ ). 
Prior anatomical studies indicated that the input and output connections of dHPC and vHPC are distinct, and that vHPC, but not dHPC, is involved in emotional behavior (Fanselow and Dong, 2010; Moser and Moser, 1998). To determine which portion of the HPC is involved in the synaptic consolidation of contextual memory, we stereotaxically delivered CaMKII $\alpha$ ::HA-hM4Di-IRES-mCitrine virus into dHPC or vHPC of mouse brain, and assessed their role in synaptic consolidation using the aforementioned fear-conditioning protocol. Following treatment with CNO, mice expressing HA-hM4Di virus in the vHPC showed a significant decrease in freezing during the retrieval of contextual memory $(t(18)=2.7, p=0.015)$, although mice expressing HA-hM4Di virus in the dHPC were unaffected by CNO $(t(12)=0.266, p=0.795)$, compared with EGFP control mice (Figure 5c). Our data demonstrate that suppressing glutamatergic neuronal activity in the vHPC, but not dHPC, selectively impairs synaptic consolidation of contextual memory.

We thus demonstrate that the time window immediately after training was critical for the synaptic consolidation in the HPC, and vHPC, but not in dHPC principal cells, had a major role during this process. To further confirm the time-specific effect of $\mathrm{CNO}$ on synaptic consolidation in vHPC, we stereotaxically delivered CaMKII $\alpha:$ HA-hM4DiIRES-mCitrine virus into the vHPC of a separate cohort of mice and administered $2 \mathrm{mg} / \mathrm{kg} \mathrm{CNO} 30 \mathrm{~min}$ before training. We found that there was no significant difference in contextual freezing between HA-hM4Di viral-delivery mice and EGFP control mice $(t(16)=0.167, p=0.87$; Figure $5 \mathrm{~d})$. The results show that suppressing glutamatergic neurons in the vHPC immediately after, but not before, training impairs synaptic consolidation of contextual memory.

\section{DISCUSSION}

The main finding of this paper is that the acute chemogenetic inactivation of ventral hippocampal principal cells is sufficient to impair synaptic consolidation of memory using a contextual fear-conditioning paradigm. These findings demonstrate a novel and striking cell type and regionally selective modulation of synaptic consolidation of memory. We also report and characterize a Gi-DREADD (hM4Di) transgenic mouse line for in vivo manipulation of neuronal activity in freely moving mice. Finally, these findings serve to validate the use of chemogenetic technology such as hM4Di to reversibly and non-invasively modulate the activity of hippocampal neurons.

Synaptic consolidation is a process thought to be required to stabilize synaptic changes after learning and has been reported to involve gene expression, de novo protein synthesis, and synaptic restructuring (Dudai, 2004; Frankland and Bontempi, 2005). Previous studies (Bourtchouladze et al, 1998; Freeman et al, 1995; Igaz et al, 2002; Quevedo et al, 1999) have shown that there are two critical time windows for the synaptic consolidation of contextual memory: around the time of training and 3-6h after training. In the present study, we found that inactivating hippocampal neurons by $\mathrm{CNO}$ administration in the initial $6 \mathrm{~h}$ immediately after training led to selective impairment of contextual fear conditioning. However, CNO administration beyond this 6 -h window or immediately before training was unable to block synaptic consolidation. The brief window of synaptic consolidation is not only important for recent contextual memory (Bourtchouladze et al, 1998; Freeman et al, 1995; Igaz et al, 2002; Quevedo et al, 1999) but also for 1-month-old remote contextual memory as shown in our paper, suggesting that the initial synaptic consolidation phase is critical for subsequent system consolidation.

In the current study, we selectively blocked the synaptic consolidation by chemogenetic inactivation of hippocampal neurons immediately after training. We posit that there are two possible cellular or molecular mechanisms for the Gi-DREADD-mediated disruption of synaptic consolidation. First, as the NMDA/ $\alpha \mathrm{CaMKII}$ signaling pathway is crucial for the long-term potentiation (LTP) and memory consolidation (Mayford et al, 1995; Rampon et al, 2000; Silva et al, 1992; Tang et al, 1999; Tsien et al, 1996), hM4Di receptor could activate a GIRK, induce hyperpolarization, and block action potential firing in hippocampal neurons (Armbruster et al, 2007). As hyperpolarization of neurons prevents the activation of NMDA receptors, it could subsequently blocks LTP and memory consolidation (Malinow and Miller, 1986). Second, the cAMP/PKA/CREB signaling transduction pathway has been shown to be involved in the maintenance of LTP and synaptic consolidation (Abel et al, 1997; Kida et al, 2002; Pineda et al, 2004; Pittenger et al, 2002; Wang et al, 2004; Wong et al, 1999). As the Gi-DREADD receptor is coupled to the $G_{i / o}$ protein, when it is activated by $\mathrm{CNO}$, the $\mathrm{G}_{\mathrm{i} / \mathrm{o}}$ protein will be released and it will diminish the activity of adenylyl cyclase (AC). A decrease in intracellular cAMP concentration could thereby prevent the activation of $\mathrm{PKA}$ and subsequent phosphorylation of CREB. Ultimately, CREB-mediated gene expression, which is important for the memory consolidation (Kandel, 2001, 2012), is disrupted. Although the current studies do not directly address the mechanism(s) involved, it is possible that Gi-DREADD might compromise both signaling pathways and thereby attenuate synaptic consolidation.

The HPC has been shown to be functionally defined along its dorsoventral axis (Fanselow and Dong, 2010; Moser and Moser, 1998; Pitkanen et al, 2000; Richmond et al, 1999; Yoon and Otto, 2007). The dHPC receives a dense input from the lateral entorhinal cortex and is proposed to participate in processing exteroceptive sensory information, whereas the $\mathrm{vHPC}$ receives inputs from the medial entorhinal cortex and is proposed to assist in processing interoceptive sensory information (Amaral, 1995). Thus, the dHPC is thought to have a predominant role in spatial memory, whereas the vHPC is thought to be important for the consolidation of memories associated with anxiety and emotional behavior (Fanselow and Dong, 2010). We have built on and extended these prior studies by definitively showing, by selective chemogenetic inactivation of the dHPC or vHPC during synaptic consolidation, that vHPC, but not dHPC, was involved in the consolidation of contextual fear memory. Our findings clearly support the concept of a functional differentiation of the HPC along the dorsoventral axis and confirm the 
role of the vHPC in the synaptic consolidation of contextual memory.

Further, while some prior reports in the literature suggested a role for the dHPC in the learning or/and memory for contextual fear (Debiec et al, 2002; Frankland et al, 1998; Maren et al, 1997; McNish et al, 2000), others found a role for the vHPC (Ambrogi Lorenzini et al, 1997; Bast et al, 2001; Donley et al, 2005; Hobin et al, 2006; Rudy and Matus-Amat, 2005; Trivedi and Coover, 2004; Zhang et al, 2001). Our results using chemogenetic technology clearly implicate the vHPC and not dHPC, in the consolidation of contextual fear memory. There are several lines of evidence from prior studies that lend support to these findings. First, as a component of context, olfactory information is believed to be processed in the vHPC but not in dHPC (Kent et al, 2007). In fMRI studies, there is a greater activation of ventral (rodent)/anterior (human) HPC when odor information is processed (Cerf-Ducastel and Murphy, 2001; Kent et al, 2007). Further, vHPC lesions have more pronounced effect on olfactory cues than visual or spatial cues, whereas the opposite is found for dHPC lesions (Blanchard et al, 2005; Hunsaker et al, 2008; Kesner et al, 2011; Levita and Muzzio, 2010). Therefore, inactivation of vHPC may impair the consolidation of olfactory memory, and reduced behavioral freezing during the subsequent contextual test. Second, the vHPC has direct and extensive connections with the amygdala, whereas the dHPC gains access to amygdala only through its connections with vHPC (Pitkanen et al, 2000). Stimulation of the efferents projecting from vHPC to amygdala regulates synaptic plasticity in the amygdala, and lesioning of these efferents prevents contextual fear conditioning (Maren and Fanselow, 1995). Therefore, chemogenetic inactivation of vHPC by Gi-DREADD may disrupt the normal communication between the vHPC and amygdala, block the converging contextual information from both vHPC and dHPC to amygdala, and impair the consolidation of contextual memory.

Previous studies (Bannerman et al, 2003; Kjelstrup et al, 2002; Yoon and Otto, 2007) have reported that lesions or pharmacological manipulation of vHPC can alter anxiety and locomotor activity that may non-specifically affect the performance of behavioral freezing during tests of conditioned fear. In the present study, it is highly unlikely that the deficit in consolidation of contextual memory was due to alterations of anxiety or locomotor activity as these were measured and found to be unaffected by $\mathrm{CNO}$ injection (Supplementary Figure S3).Thus, our findings clearly demonstrate that deficits in context-dependent freezing following selective chemogenetic inactivation of vHPC principal neurons reflect the impairment of synaptic consolidation, and not a non-specific alteration of anxiety or locomotor behavior.

In summary, we demonstrate that vHPC principle neurons are key drivers for synaptic consolidation of memory.

\section{FUNDING AND DISCLOSURE}

This work was supported by U19MH82441 and RO1MH61887 to Dr Roth as well as the Michael Hooker Chair of Pharmacology to Dr Roth. Imaging was supported by the Confocal and Multiphoton Imaging Core of NINDS Center Grant P30 NS045892. Dr Roth has consulted for Otsuka Pharmaceuticals, Merck, Sunovion, Albany Molecular Research, Pfizer Pharmaceuticals, Finnegan, Henderson, Farabow, Garrett And Dunner, L.l.p, Venrock, SeaChange Pharmaceuticals, and RuiYi Pharmaceuticals. Dr Roth also receives compensation for serving as Associate Editor of the Journal of Clinical Investigation. The remaining authors declare no conflict of interest.

\section{ACKNOWLEDGEMENTS}

We thank Vladimir Ghukasyan for his excellent imaging technical assistance.

\section{REFERENCES}

Abbas AI, Yadav PN, Yao WD, Arbuckle MI, Grant SG, Caron MG et al (2009). PSD-95 is essential for hallucinogen and atypical antipsychotic drug actions at serotonin receptors. J Neurosci 29: 7124-7136.

Abel T, Nguyen PV, Barad M, Deuel TA, Kandel ER, Bourtchouladze R (1997). Genetic demonstration of a role for PKA in the late phase of LTP and in hippocampus-based long-term memory. Cell 88: 615-626.

Agranoff BW, Davis RE, Brink JJ (1965). Memory fixation in the goldfish. Proc Natl Acad Sci USA 54: 788-793.

Amaral DG W, MP (1995). Hippocampal formation. In Paxinos G ed. The Rat Nervous System. Academic Press: San Diego.

Ambrogi Lorenzini CG, Baldi E, Bucherelli C, Sacchetti B, Tassoni G (1997). Role of ventral hippocampus in acquisition, consolidation and retrieval of rat's passive avoidance response memory trace. Brain Res 768: 242-248.

Armbruster BN, Li X, Pausch MH, Herlitze S, Roth BL (2007). Evolving the lock to fit the key to create a family of $G$ proteincoupled receptors potently activated by an inert ligand. Proc Natl Acad Sci USA 104: 5163-5168.

Bannerman DM, Grubb M, Deacon RM, Yee BK, Feldon J, Rawlins JN (2003). Ventral hippocampal lesions affect anxiety but not spatial learning. Behav Brain Res 139: 197-213.

Bast T, Zhang WN, Feldon J (2001). The ventral hippocampus and fear conditioning in rats. Different anterograde amnesias of fear after tetrodotoxin inactivation and infusion of the GABA(A) agonist muscimol. Exp Brain Res 139: 39-52.

Blanchard DC, Canteras NS, Markham CM, Pentkowski NS, Blanchard RJ (2005). Lesions of structures showing FOS expression to cat presentation: effects on responsivity to a Cat, Cat odor, and nonpredator threat. Neurosci Biobehav Rev 29: 1243-1253.

Bourtchouladze R, Abel T, Berman N, Gordon R, Lapidus K, Kandel ER (1998). Different training procedures recruit either one or two critical periods for contextual memory consolidation, each of which requires protein synthesis and PKA. Learn Mem 5: 365-374.

Cerf-Ducastel B, Murphy C (2001). fMRI activation in response to odorants orally delivered in aqueous solutions. Chem Senses 26: 625-637.

Chen X, Garelick MG, Wang H, Lil V, Athos J, Storm DR (2005). PI3 kinase signaling is required for retrieval and extinction of contextual memory. Nat Neurosci 8: 925-931.

Debiec J, LeDoux JE, Nader K (2002). Cellular and systems reconsolidation in the hippocampus. Neuron 36: 527-538.

Donley MP, Schulkin J, Rosen JB (2005). Glucocorticoid receptor antagonism in the basolateral amygdala and ventral hippocampus 
interferes with long-term memory of contextual fear. Behav Brain Res 164: 197-205.

Dudai Y (2004). The neurobiology of consolidations, or, how stable is the engram? Annu Rev Psychol 55: 51-86.

Duncan CP (1949). The retroactive effect of electroshock on learning. J Comp Physiol Psychol 42: 32-44.

Fanselow MS, Dong HW (2010). Are the dorsal and ventral hippocampus functionally distinct structures? Neuron 65: 7-19.

Frankland PW, Bontempi B (2005). The organization of recent and remote memories. Nat Rev Neurosci 6: 119-130.

Frankland PW, Cestari V, Filipkowski RK, McDonald RJ, Silva AJ (1998). The dorsal hippocampus is essential for context discrimination but not for contextual conditioning. Behav Neurosci 112: 863-874.

Frankland PW, O'Brien C, Ohno M, Kirkwood A, Silva AJ (2001). Alpha-CaMKII-dependent plasticity in the cortex is required for permanent memory. Nature 411: 309-313.

Freeman FM, Rose SP, Scholey AB (1995). Two time windows of anisomycin-induced amnesia for passive avoidance training in the day-old chick. Neurobiol Learn Mem 63: 291-295.

Grecksch G, Matthies H (1980). Two sensitive periods for the amnesic effect of anisomycin. Pharmacol Biochem Behav 12: 663-665.

Hobin JA, Ji J, Maren S (2006). Ventral hippocampal muscimol disrupts context-specific fear memory retrieval after extinction in rats. Hippocampus 16: 174-182.

Hunsaker MR, Fieldsted PM, Rosenberg JS, Kesner RP (2008). Dissociating the roles of dorsal and ventral CA1 for the temporal processing of spatial locations, visual objects, and odors. Behav Neurosci 122: 643-650.

Igaz LM, Vianna MR, Medina JH, Izquierdo I (2002). Two time periods of hippocampal mRNA synthesis are required for memory consolidation of fear-motivated learning. J Neurosci 22: 6781-6789.

Kandel ER (2001). The molecular biology of memory storage: a dialogue between genes and synapses. Science 294: 1030-1038.

Kandel ER (2012). The molecular biology of memory: cAMP, PKA, CRE, CREB-1, CREB-2, and CPEB. Mol Brain 5: 14.

Kent K, Hess K, Tonegawa S, Small SA (2007). CA3 NMDA receptors are required for experience-dependent shifts in hippocampal activity. Hippocampus 17: 1003-1011.

Kesner RP, Hunsaker MR, Ziegler W (2011). The role of the dorsal and ventral hippocampus in olfactory working memory. Neurobiol Learn Mem 96: 361-366.

Kida S, Josselyn SA, Pena de Ortiz S, Kogan JH, Chevere I, Masushige $S$ et al (2002). CREB required for the stability of new and reactivated fear memories. Nat Neurosci 5: 348-355.

Kjelstrup KG, Tuvnes FA, Steffenach HA, Murison R, Moser EI, Moser MB (2002). Reduced fear expression after lesions of the ventral hippocampus. Proc Natl Acad Sci USA 99: $10825-10830$

Levita L, Muzzio I (2010). A role of the hippocampus in goaloriented tasks requiring retrieval of spatial versus non-spatial information. Neurobiol Learn Mem 93: 581-588.

Lisman J, Schulman H, Cline H (2002). The molecular basis of CaMKII function in synaptic and behavioural memory. Nat Rev Neurosci 3: 175-190.

Lisman JE, Grace AA (2005). The hippocampal-VTA loop: controlling the entry of information into long-term memory. Neuron 46: 703-713.

Malinow R, Miller JP (1986). Postsynaptic hyperpolarization during conditioning reversibly blocks induction of long-term potentiation. Nature 320: 529-530.

Maren S, Aharonov G, Fanselow MS (1997). Neurotoxic lesions of the dorsal hippocampus and Pavlovian fear conditioning in rats. Behav Brain Res 88: 261-274.
Maren S, Fanselow MS (1995). Synaptic plasticity in the basolateral amygdala induced by hippocampal formation stimulation in vivo. I Neurosci 15: 7548-7564.

Maren S, Fanselow MS (1996). The amygdala and fear conditioning: has the nut been cracked? Neuron 16: 237-240.

Mayford M, Bach ME, Huang YY, Wang L, Hawkins RD, Kandel ER (1996). Control of memory formation through regulated expression of a CaMKII transgene. Science 274: 1678-1683.

Mayford M, Wang J, Kandel ER, O’Dell TJ (1995). CaMKII regulates the frequency-response function of hippocampal synapses for the production of both LTD and LTP. Cell 81: 891-904.

McGaugh JL (2000). Memory-a century of consolidation. Science 287: 248-251.

McNish KA, Gewirtz JC, Davis M (2000). Disruption of contextual freezing, but not contextual blocking of fear-potentiated startle, after lesions of the dorsal hippocampus. Behav Neurosci 114: 64-76.

Moser MB, Moser EI (1998). Functional differentiation in the hippocampus. Hippocampus 8: 608-619.

Müller GE, Pilzecker A (1900). Experimentelle Beiträge zur Lehre vom Gedächtnis. Z Psychol Ergänzungsband 1: 1-300.

Pineda VV, Athos JI, Wang H, Celver J, Ippolito D, Boulay G et al (2004). Removal of G(ialpha1) constraints on adenylyl cyclase in the hippocampus enhances LTP and impairs memory formation. Neuron 41: 153-163.

Pitkanen A, Pikkarainen M, Nurminen N, Ylinen A (2000). Reciprocal connections between the amygdala and the hippocampal formation, perirhinal cortex, and postrhinal cortex in rat. A review. Ann N Y Acad Sci 911: 369-391.

Pittenger C, Huang YY, Paletzki RF, Bourtchouladze R, Scanlin H, Vronskaya S et al (2002). Reversible inhibition of CREB/ATF transcription factors in region CA1 of the dorsal hippocampus disrupts hippocampus-dependent spatial memory. Neuron 34: 447-462.

Quevedo J, Vianna MR, Roesler R, de-Paris F, Izquierdo I, Rose SP (1999). Two time windows of anisomycin-induced amnesia for inhibitory avoidance training in rats: protection from amnesia by pretraining but not pre-exposure to the task apparatus. Learn Mem 6: 600-607.

Rampon C, Tang YP, Goodhouse J, Shimizu E, Kyin M, Tsien JZ (2000). Enrichment induces structural changes and recovery from nonspatial memory deficits in CA1 NMDAR1-knockout mice. Nat Neurosci 3: 238-244.

Richmond MA, Yee BK, Pouzet B, Veenman L, Rawlins JN, Feldon J et al (1999). Dissociating context and space within the hippocampus: effects of complete, dorsal, and ventral excitotoxic hippocampal lesions on conditioned freezing and spatial learning. Behav Neurosci 113: 1189-1203.

Rudy JW, Matus-Amat P (2005). The ventral hippocampus supports a memory representation of context and contextual fear conditioning: implications for a unitary function of the hippocampus. Behav Neurosci 119: 154-163.

Shimizu E, Tang YP, Rampon C, Tsien JZ (2000). NMDA receptordependent synaptic reinforcement as a crucial process for memory consolidation. Science 290: 1170-1174.

Silva AJ, Paylor R, Wehner JM, Tonegawa S (1992). Impaired spatial learning in alpha-calcium-calmodulin kinase II mutant mice. Science 257: 206-211.

Sweatt JD (1999). Toward a molecular explanation for long-term potentiation. Learn Mem 6: 399-416.

Tang YP, Shimizu E, Dube GR, Rampon C, Kerchner GA, Zhuo M et al (1999). Genetic enhancement of learning and memory in mice. Nature 401: 63-69.

Trivedi MA, Coover GD (2004). Lesions of the ventral hippocampus, but not the dorsal hippocampus, impair conditioned fear expression and inhibitory avoidance on the elevated T-maze. Neurobiol Learn Mem 81: 172-184. 
Tsien JZ, Huerta PT, Tonegawa S (1996). The essential role of hippocampal CA1 NMDA receptor-dependent synaptic plasticity in spatial memory. Cell 87: 1327-1338.

Wang H, Ferguson GD, Pineda VV, Cundiff PE, Storm DR (2004). Overexpression of type-1 adenylyl cyclase in mouse forebrain enhances recognition memory and LTP. Nat Neurosci 7: 635-642.

Wong ST, Athos J, Figueroa XA, Pineda VV, Schaefer ML, Chavkin CC et al (1999). Calcium-stimulated adenylyl cyclase activity is critical for hippocampus-dependent long-term memory and late phase LTP. Neuron 23: 787-798.

Yoon T, Otto T (2007). Differential contributions of dorsal vs ventral hippocampus to auditory trace fear conditioning. Neurobiol Learn Mem 87: 464-475.

Zhang WN, Bast T, Feldon J (2001). The ventral hippocampus and fear conditioning in rats: different anterograde amnesias of fear after infusion of N-methyl-D-aspartate or its noncompetitive antagonist MK-801 into the ventral hippocampus. Behav Brain Res 126: 159-174.

Supplementary Information accompanies the paper on the Neuropsychopharmacology website (http://www.nature.com/npp) 